\title{
COVID-19 disaster and employment generation program in a developing economy
}

\author{
Sarbajit Chaudhuri ${ }^{1} \cdot$ Sushobhan Mahata ${ }^{1}$ (D) Salonkara Chaudhuri ${ }^{2}$
}

Accepted: 23 October 2021 / Published online: 2 December 2021

(c) The Author(s), under exclusive licence to Institute for Social and Economic Change 2021

\begin{abstract}
We develop a three-sector Harris-Todaro (HT)-type model for a developing economy to analyse the failure of the employment generation program in the rural sector as a policy response to counter Covid-19-induced reverse migration of labour. First, we distinguish between two alternative modes of implementation of the program and show how they produce diverse outcomes on both unemployment and welfare. Welfare is measured in terms of Sen's (Sen, J Public Econ 4:387-403, 1974) index which is inequality (distributional) sensitive. If the authority's sole target is to lower unemployment, the policy fails miserably because it not only raises unemployment but also worsens welfare. On the contrary, if the policy aims at both rural infrastructure development and additional employment creation, it does not necessarily worsen social welfare. However, the rural employment generation program may turn out to be counterproductive in the latter case provided the urban region is relatively more labour abundant vis-a-vis the entire rural region. Numerical examples are constructed to validate the sufficient and necessary condition leading to the counterproductive outcome. Finally, we have advocated in favour of a composite policy that might succeed in minimizing further possible damage of the COVID-19 disaster.
\end{abstract}

Keywords Employment generation · Unemployment - Social welfare · COVID-19 disaster

JEL Classification I38 $\cdot \mathrm{J} 61 \cdot \mathrm{J} 68 \cdot \mathrm{R} 13$

Sushobhan Mahata

sushobhanmahata@gmail.com

Sarbajit Chaudhuri

sceco@caluniv.ac.in

Salonkara Chaudhuri

salonkara.chaudhuri@uqconnect.edu.au

1 Department of Economics, University of Calcutta, Kolkata, India

2 Department of Economics, Faculty of Business and Law, University of Queensland, Brisbane, Australia 


\section{Introduction}

Given the recent COVID-19 disaster, a large rural-based developing economy like India needs to undertake the correct migration policy so that the spread of the disease could be restricted. However, the authority although initially had adopted to lockdown policy, it later resorted to unlock policy that turned out to be disastrous and led to the spread of the disease even to the hitherto unaffected rural areas.

According to data released by CMIE and published in Economic Times on August 19, 2020, we find that the disaster and the subsequent lockdown measures undertaken by the Indian authority resulted in an unprecedented increase in the unemployment rates, especially during April and May. With businesses shuttered causing a huge wave of reverse migration, the country's overall unemployment rate rose as high as 27.11 for the week that ended May 7. It has taken till August for the joblessness rate to return to pre-COVID-19 levels. ${ }^{1}$

According to DBS Report Published in Economic Times on 22 July 2020, the Pandemic is expected to decrease India's GDP by 6 per cent in FY21. ${ }^{2}$ The disaster struck India at a time when the economy was going through economic distress because of demand scarcity. After the arrival of the menace, many production units were temporarily shut during the initial lockdown period. Many workers had lost their jobs and did not receive any public financial support for sustenance. The authority allowed them to reverse migrate to their villages (sector/region 1). They migrated with the hope of having better living conditions at their places of origin. Some of the migrated workers were already in a diseased state. Once they had reached homes, the authority instead of providing them direct financial support created additional jobs for enabling them to sustain themselves during this period. Although the competitive rural/regional wage marginally increased, the migrated workers had found that their average income in villages was far less than their average (expected) income at the workplace (sector/region 2). During the unlock situation, many of them returned to their workplaces. As they were allowed to migrate once more, many of them did not find jobs at their respective workplaces because during the different unlock phases, the demand for labour in the metro cities has only marginally increased. Hence, the unemployment problem (in region 2) aggravated even further.

The migration policy undertaken by the authority during the lockdown stage was completely wrong. The faulty policy had taken its toll and produced devastating consequences on society. The community infection had spread over the previously least affected areas, thereby increasing both asymptomatic and active Corona cases along with overall death count.

In this backdrop, we have developed a three-sector Beladi and Naqvi (1988) (BN, hereafter)-type Harris-Todaro (1970) (HT, hereafter)-type model for showing that how the migration policy of the government was faulty and what could have been done instead of the employment generation program in restricting the spread of the disease throughout the country. ${ }^{3}$ The economy is distorted with the presence of open urban unemployment and

\footnotetext{
1 See ETNOWNEWS (2020). https://www.timesnownews.com/business-economy/economy/article/howthe-COVID-19-outbreak-has-affected-the-joblessness-rate-in-india-explained-in-4-charts/634284.

${ }^{2}$ See https://economictimes.indiatimes.com/news/economy/indicators/pandemic-to-bite-deeply-gdp-toshrink-by-6-per-cent-in-fy21-report/articleshow/77106074.cms.

3 The HT structure is criticized because of the undesirable properties like growth in labour (capital) endowment lowers (raises) the unemployment problem although highly populated (capital scarcity) is blamed for
} 
credit market imperfection. The stylized economic structure assumed resembles a typical developing economy which is characterized by the presence of wage disparity and unemployment; therefore, national income (aggregative measure) as a proxy of welfare may lead to overestimation of result, and hence the distribution of income between different groups of wage earners and those unemployed earning zero wage rate must be adjusted with national income. Therefore, the welfare of this economy is measured using Sen (1974) index which is sensitive to income distribution (inequality).

We have considered two policies depending on the target of the authority. This first policy is designed to restrict labour mobility across the country, while the second one is to provide temporary relief to the already reverse migrated workers in the villages through the creation of additional jobs. We have found that while relaxing the migration policy raises the rural wage, the policy unequivocally worsens both the unemployment situation of the country and social welfare. On the other hand, the creation of additional jobs in the villages might produce exactly the same effects. From the perspective of both social welfare and regional unemployment, both policies turn out to be counterproductive. Finally, using this framework, we have designed a composite policy that could succeed in minimizing further possible damage of the COVID-19 disaster.

\section{A brief survey of literature, motivation and main findings}

There has been a huge empirical literature that has identified faulty design, operational inadequacy and poor implementation as some of the factors responsible for the failure of the program. ${ }^{4}$ On the other hand, some theoretical works have attempted in finding out optimal wage under the scheme and its consequence on the rural labour market and welfare of the working families. ${ }^{5}$ However, all of them have resorted to the partial equilibrium analysis and have not discussed the efficacy of the policy in mitigating the unemployment problem, before and after the COVID-19 disaster.

To the best of our knowledge, no multi-sector general equilibrium structure has yet been developed that can analyse the efficacy of the policies in controlling the spread of the disease. A couple of salient features of the developing economies are the existence of credit market dualism, rural-urban (regional) migration and (regional) unemployment. Because of intersectoral (regional) wage differential, many of the rural (region 1) workers decide to migrate to the urban sector (region 2). Besides, there is also capital market distortion that is reflected through the presence of intersectoral interest rate differential. However, all of them do not get employed there (in region 2). Consequently, the urban (regional) unemployment problem arises. In the migration equilibrium, the expected urban (region 2) wage and rural (region 1) wage become equal. Therefore, it goes without saying that for examining the efficacy of a policy, one has to recourse to a dualistic BN (1988)-type general

\footnotetext{
Footnote 3 (continued)

the prevalence of the high unemployment problem in such a country. In BN, because of the presence of a specific factor in sector 1 , these undesirable problems properties could at least be partially overcome

4 Some of the notable works are by Datar (2007), Ambasta et al (2008), Imbert and Papp (2015), Nagaraj et al (2016), Bhattacharjee (2017), Pankaj (2017), Zimmermann (2012), Berg et al. (2012) etc.

5 See for example, Basu (2013), Basu et al (2009) and Imbert and Papp (2015) etc.
} 
equilibrium model. ${ }^{6}$ One might criticize our paper because of considering an HT structure. However, we have already pointed out that the BN structure is free of such criticisms. ${ }^{7}$

\section{Description of the economy and policy instruments}

We consider a $3 \times 3$ H-T-type dual economy model for a small open developing country with COVID-19 disaster. ${ }^{8}$ Three basic factors of production are, labour $(L)$, capital $(K)$, arable land $(N)$. The endowments of these inputs are exogenously fixed at $\bar{L}, \bar{K}$ and $\bar{N}$, respectively. Besides, there is a fixed amount of barren land, $N^{*}$ (in region 1 ) that cannot be used for agriculture. There are two broad sectors, rural sector (region 1) and urban sector (region 2). The rural sector (region 1) is further subdivided into two subsectors, the agriculture sector (sector 1) and one non-traded public sector (sector $G$ ). Sector 1 uses, arable land $(N)$, labour and capital to produce an agricultural commodity, $X_{1}$ while the urban sector (in region 2) produces a manufacturing commodity, $X_{2}$ using labour and capital. The capital-output ratio in sector $1, \bar{a}_{K 1}$ is technologically fixed. ${ }^{9}$ Finally, sector $G$ (in region 1 ) produces a non-traded public commodity, $X_{G}$ using a fixed-coefficient technology of production. One unit of $X_{G}$ requires one unit of barren land and labour each and $\bar{a}_{K G}$ units of capital. The chosen value of $\bar{a}_{K G}$ is either zero or positive depending on the type of policy that the authority decides to undertake. The quantity of production $\bar{X}_{G}$ is also decided by the government. The unit price of $\bar{X}_{G}$, denoted by $P_{G}$, is then equal to its unit cost of production, $\left(\bar{W}+\bar{R}+r \bar{a}_{K G}\right)$ where $\bar{W}(>W)$ and $\bar{R}$ are the government determined wage rate and rental to owners of labour and barren land, $N^{*}$ in region 1, respectively.

We conceptualize sector $G$ as a temporary public sector scheme (e.g., public employment generation programme) for giving some relief to the already migrated workers (in region 1) that might indirectly affect the production of the traded commodities. ${ }^{10}$ The unit cost of production in sector $G\left(\bar{W}+\bar{R}+r \bar{a}_{K G}\right)$ is financed through lump-sum taxes on factor incomes. On the other hand, because of the presence of capital market distortion, the informal interest rate faced by the agriculture sector (sector 1) in the rural region is $r^{*}$ which is greater than the competitive (formal) interest rate in the urban sector $r$.

\footnotetext{
${ }^{6}$ Ravallion (1990) is a rare exception where in terms of an HT structure, consequence of public work program on both labour displacement in agriculture and rural income has been studied. However, the analysis draws heavily on a couple of over-simplistic assumptions like uniform wages and homogenous commodities across sectors and labour to be the only input of production, etc.

${ }^{7}$ See footnote 3 in this context.

${ }^{8}$ One possible pattern of international trade of this small open economy could be as follows. The country exports commodity 1 while imports commodity 2 . However, it should be clearly stated that the qualitative results of the model are completely independent of the trade pattern of the economy in the absence of any commodity market distortion.

${ }^{9}$ Although this is a simplifying assumption, it is not completely without any basis. Agriculture requires inputs like fertilizers, pesticides, weedicides, etc., that are to be used in recommended doses. If capital is used to purchase those inputs, $a_{K 1}$ is technologically constant. However, labour and land are substitutes and the production function displays the CRS property in these two inputs.

${ }^{10}$ It is needless to point out that the authority in a developing economy spends a substantial amount of its resources on major irrigation projects, construction of roads, land development, etc., for building up social infrastructure that is conducive to growth and employment. For this, the public sector acquires barren land which is conducive for improving the productivity of the land used in agriculture sector. MGNREGA (2012)is one such project which motivates the working of sector $G$ in our model (see MNREGA Sameeksha 2012).
} 
The migration policy is captured through a change in $\gamma$, where $\gamma$ is the subjective discounting factor on the urban wage rate $W^{*}$ and thus $\gamma W^{*}$ is the discounted urban wage rate. ${ }^{11}$ On the other hand, an employment generation policy is encapsulated through a change in $\bar{X}_{G}{ }^{12}$ At the chosen value of $\bar{a}_{K G}$, the authority attempts in temporarily employing at least some of the already migrated workers at the wage rate, $\bar{W}$. This policy can be encapsulated through an increase in the output of sector $G$. This expansion of the public sector works can be either productive or unproductive depending on the choice of $\bar{a}_{K G}$. The policy is productive if some amount of capital $\left(\bar{a}_{K G}>0\right)$ might be utilized along with labour and barren land for infrastructure development in region 1 that in turn could raise the efficiency of arable land, $N$, denoted by, $h$, through positive production externalities. On the other hand, the policy remains unproductive if no capital is employed (i.e., $\left.\bar{a}_{K G}=0\right) .{ }^{13}$ In both cases, not only the endowment of capital available to the traded sectors, $\left(\bar{K}-\bar{a}_{K G} \bar{X}_{G}\right)$ changes but also nothing is contributed to GDP unless the effect of externalities on the efficiency of arable land is sufficiently high.

Workers in agriculture (sector 1 ) receive a competitive wage, $W$, in region 1 , while their counterparts in the urban sector (region 2) receive an exogenously fixed high wage, $W^{*}$. Because of intersectoral (interregional) wage differential $\left(W^{*}-W\right)$, some of the rural workers migrate to the urban sector (region 2). However, the size of the urban labour force exceeds the number of available jobs (in region 2). Consequently, involuntary unemployment arises in the sector (region) 2 .

\section{The model, equational structure and general equilibrium}

Assuming that $\bar{X}_{G}>0$, the efficiency (productivity) function of $N$ is given by the following.

$$
h\left(\bar{a}_{K G} \bar{X}_{G}\right)\left\{\begin{array}{l}
>1 \text { for } \bar{a}_{K G}>0 \\
=1 \text { for } \bar{a}_{K G}=0
\end{array}\right.
$$

and $h^{\prime}()>$.0 for $\bar{a}_{K G}>0$.

We define $E_{h}(\geq 0)$ as the elasticity of the efficiency function where ${ }_{E_{h}}=\left[\left(\frac{d h}{d\left(\bar{a}_{K G} \bar{x}_{G}\right)}\right)\left(\frac{\left(\bar{a}_{K G} \bar{X}_{G}\right)}{h}\right)\right]$

\footnotetext{
${ }^{11}$ Consider the situation of COVID-19-induced urban economic crisis which increased uncertainty and insecurity among unskilled workers, and thus they would revise downward their expectation about the urban wage rate which implies an exogenous fall in the value of the discounting factor $\gamma$. This effect is similar to the concept of wage cut or the Keynes effect. We are grateful to one of the reviewers for pointing out this possible interpretation of $\gamma$. This had been further elaborated in footnote 17 .

${ }^{12}$ Here we assume that the size of the public sector is exogenous in the model. Public sector programmes such as the MGNREGP had turned to supply-driven top-down which is controlled exogenously by the government rather than remaining demand-driven bottom-up as it was initially envisaged in the act of MGNREGA 2005 (see Mukhopadhyay et al., 2015; Bhattacharjee 2017).

${ }^{13}$ Sector $G$ represents the public sector scheme targeted towards creation of job in the rural region. MGNREGP is one such public sector scheme, however, overtime it turned to mere creation of unproductive jobs in terms of digging the pit and filling it up. These works do not create any sustainable rural asset and usually no capital is needed to be employed for such unproductive works, thus, $\bar{a}_{K G}=0$. On the other hand, considerable amount of capital is being used under the scheme for creation of productive rural asset such as creation of rural roads, large canals etc., thus, $\bar{a}_{K G}>0$. See Ambasta, Shankar and Shah (2008), Bhattacharjee (2017) and Pankaj (2017), etc., for detailed discussion.
} 
The usual zero-profit conditions for the three sectors are as follows.

$$
\begin{gathered}
W a_{L 1}+R a_{N 1}+r^{*} \bar{a}_{K 1}=P_{1} \\
W^{*} a_{L 2}+r a_{K 2}=P_{2} \\
\left(\bar{W}+\bar{R}+r \bar{a}_{K G}\right)=P_{G}
\end{gathered}
$$

While the producers in sector 1 face an imperfect capital market and borrow capital (working capital) at the high informal interest rate, $r^{*}$, the producers in the formal sector (sector 2) receive credit from the organized credit market at the low market interest rate, $r$. The two-interest rate, $r^{*}$ and $r$ are related by the following equation that captures capital market imperfection in the economy.

$$
r^{*}=\beta r, \text { with } \beta>1
$$

$\beta>1$ signifies the existence and degree of credit market imperfection. ${ }^{14,15}$ It is to be noted that sector $G$ is completely government-controlled. Hence, the return to capital in this sector is $r$.

The full-employment conditions for capital and arable land are the following, respectively.

$$
\begin{gathered}
\bar{a}_{K 1} X_{1}+a_{K 2} X_{2}+\bar{a}_{K G} \bar{X}_{G}=\bar{K} \\
a_{N 1} X_{1}=h\left(\bar{a}_{K G} \bar{X}_{G}\right) N
\end{gathered}
$$

where $h$ is the efficiency of arable land.

The labour endowment equation of the economy is as follows.

$$
a_{L 1} X_{1}+a_{L 2} X_{2}+\bar{X}_{G}+L_{U}=\bar{L}
$$

where $L_{U}$ is the magnitude of unemployed workers in region 2 .

The Harris-Todaro migration equilibrium condition is given as follows.

$$
W=\left(\gamma W^{*}\right)\left(\frac{a_{L 2} X_{2}}{a_{L 2} X_{2}+L_{U}}\right) 1 \geq \gamma>0
$$

Using Eq. (8), (9) can be rewritten as follows.

\footnotetext{
${ }^{14}$ This is a very simplified way of introducing capital market imperfection in a general equilibrium model. Marjit and Acharyya (2003), Chaudhuri (2003), Mahata, Khan and Nag (2020) etc., have used this simple technique in their works. However, for a rigorous technique of informal interest rate determination starting from the optimizing behavior of the informal sector lender in a general equilibrium setting see Chaudhuri and Gupta (2014) and Chaudhuri (2017).

${ }^{15}$ It is easy to check that even if one considers a nonlinear positive relationship between $r$ and $r^{*}$ with a positive intercept term, $\beta$, like $r^{*}=[\beta+f(r)]$ with $f^{\prime}()>.0 ; \beta>0$, all of the qualitative results of the paper remain completely undisturbed. This is because it is the positive relationship between $r^{*}$ and $r$ which is required for the results of the model to remain valid. Credit market reform can still be captured through a reduction in the value of the parameter, $\beta$.
} 


$$
\gamma\left(\frac{W^{*}}{W}\right) a_{L 2} X_{2}+a_{L 1} X_{1}+\bar{X}_{G}=\bar{L}
$$

Finally, we assume that in a physical sense, sector (region) 2 and sector (region) 1 are the most and the least capital-intensive sectors (regions), respectively. Therefore, we have $\left(\frac{\lambda_{K 2}}{\lambda_{L 2}^{*}}\right)>\left(\frac{\lambda_{K G}}{\lambda_{L G}}\right)>\left(\frac{\lambda_{K 1}}{\lambda_{L 1}}\right)$.

In this general equilibrium of the whole economy, there are eight endogenous variables $W, R, r^{*}, r, P_{G}, X_{1}, X_{2}$, and $L_{U}$ with the same number of independent equations, namely, Eq. (2-8 and Eq. (10). The values of $r$ and $r^{*}$ are determined from Eq. (3) and Eq. (5), respectively. Once $r$ is determined, $P_{G}$ is determined using Eq. (4). Solving simultaneously Eq. (2, 6, 7 and 10), we get the optimal values of $W, R, X_{1}$ and $X_{2}$. The variable factor-output ratios are determined once all factor prices get determined. Finally, using Eq. (8) we can determine the unemployment level. The equilibrium values of all endogenous variables are obtained as functions of the two main policy parameters, $\gamma$ and $\bar{X}_{G}$, other than the usual parameters present in the model.

\section{The expressions for unemployment, national income and social welfare}

Subtracting Eq. (8) from Eq. (10), the magnitude of unemployment in sector (region) 2 is obtained as follows.

$$
L_{U}=\left(\frac{\gamma W^{*}}{W}-1\right) a_{L 2} X_{2}
$$

The expression for national income is given by the following.

$$
Y=\left(P_{1} X_{1}+P_{2} X_{2}\right)
$$

In the presence of a positive degree of income inequality, Sen (1974) measure of welfare is the appropriate way to measure social welfare defined by the following expression, denoted by $S,{ }^{16}$

$$
S=y(1-g)
$$

Here, $y$ is the (mean) per-capita income and $g$ is the measure of the Gini coefficient.

There are four different income groups, viz., the workers employed in sector 1 and sector $\mathrm{G}$ in the rural region (region 1 ) earning wage rate, $W$ and $\bar{W}$, respectively, workers employed in the sector 2 (region 2) earning institutionally fixed higher wage rate, $W^{*}$, and unemployed workers earning zero wage rate. In this general equilibrium economic structure, we assume that all workers are the equal-proportionate owner of capital and land of either type (barren and fertile); hence, total income from capital and land is equally

\footnotetext{
16 The usual measure of welfare is either a strict quasi-concave social utility function or national income; however, such measures are invariant to income distribution. Sen (1974) measure of welfare is sensitive to such income distribution. Sen's welfare function is characterized by the following two properties: (i) $\frac{\partial S}{\partial y}=1-g \geq 0 \forall g \leq 1$ and (ii) $\frac{\partial S}{\partial g}=-y<0 \forall y>0$. An increase in per-capita national income improves welfare; on the other hand, an increase in inequality measured by the Gini coefficient, $g$, penalizes the measure of welfare. Gupta (1993, 1994, 1988), Chakravarty and Dutta (1990), Chaudhuri (2011), and Chaudhuri and Dwibedi (2017) had also used this measure of welfare in different contexts.
} 
Table 1 Frequency distribution table showing income distribution across different groups of workers

\begin{tabular}{ll}
\hline Income & Frequency \\
\hline$W+R h() N+.\left(r^{*}-r\right) K_{1}+r \bar{K}-\left(W+r \bar{a}_{K G}\right) \bar{X}_{G}$ & $\mathrm{~L}_{1}$ \\
$\bar{W}+R h() N+.\left(r^{*}-r\right) K_{1}+r \bar{K}-\left(W+r \bar{a}_{K G}\right) \bar{X}_{G}$ & $\bar{X}_{G}$ \\
$W^{*}+R h() N+.\left(r^{*}-r\right) K_{1}+r \bar{K}-\left(W+r \bar{a}_{K G}\right) \bar{X}_{G}$ & $\mathrm{~L}_{2}$ \\
$0+R h() N+.\left(r^{*}-r\right) K_{1}+r \bar{K}-\left(W+r \bar{a}_{K G}\right) \bar{X}_{G}$ & $\mathrm{~L}_{\mathrm{U}}$ \\
\hline
\end{tabular}

distributed to each worker. Transfers are redistributed equally among workers and lumpsum taxes are borne equally by each mass of the population. Normalizing total labour force to be unity, the income distribution of the population is given by the following frequency distribution table:

Using Eq. (2)-(9), Eq. (11) and assuming total population to be unity $(\bar{L}=1)$, the mean income is given by

$$
y=W+\left(r^{*}-r\right) K_{1}+r K+R h(.) N+\overline{R X}_{G}-\left(W+r \bar{a}_{K G}+\bar{R}\right) \bar{X}_{G}
$$

Using Eq. (13) and Table 1 and after much simplifications, we can obtain the following expression

$$
y g=L_{1} \bar{X}_{G}(\bar{W}-W)+L_{1} L_{2}\left(W^{*}-W\right)+L_{1} L_{U} W+L_{2} \bar{X}_{G}\left(W^{*}-W\right)+\bar{X}_{G} L_{U} \bar{W}+L_{2} L_{U} W^{*}
$$

\section{COVID-19 disaster and Policy Consequences}

Let us consider the moment when the COVID-19 disaster just appeared as a jitter. We are interested to capture the specific effects of the COVID-19 disaster on regional migration and policy response. The disaster struck India at a time when the economy was going through economic distress because of demand scarcity. After the arrival of the menace, many production units (say, $\alpha$ fraction in sector/region 2 ) were temporarily shut at the initial lockdown period. In the meantime, workers do not receive any public financial support for sustenance, and they revised downward their expectation about the urban wage rate which implies an exogenous fall in the value of $\gamma \cdot{ }^{17}$ Fall in the value of $\gamma$ lowers the expected urban wage rate relative to the rural sector wage rate; this causes reverse migration of urban labour. The authority allowed them to reverse migrate to their villages (sector/region 1). This leads to an increase in the supply of labour in the rural region (region 1) which had put downward pressure on the rural wage rate, $W$ and overburdened the agriculture sector (sector 1).

Proposition 1 Reverse migration of labour owing to COVID-19-induced lockdown depresses the rural sector wage rate, thus burdening the rural labour market.

\footnotetext{
17 The lockdown inflicted sudden fall in income flows which caused negative expectation about future flow of income among urban workers. This originated from constrained demand owing to uncertainty which Keynes referred as "state of confidence effect". See Dasgupta and Rajeev (2020) for theoretical exposition of contraction in demand and World Bank (2020) for discussion about the COVID-19 impact on emerging market economies.
} 
Once workers reached the rural region (region 1), the authority instead of providing them direct financial support created additional jobs in the public sector (sector $G$ ) in region 1 , to enabling them to sustain during this period and to lower the burden on sector 1. The expansion of sector $G^{\prime} s$ output $\bar{X}_{G}$ in region 1 leads to the creation of some productive rural assets which improves the efficiency of arable land if sector $G$ uses some positive amount of capital along with labour and barren land; otherwise, it leads to the creation of some unproductive public good if no capital is utilized. First, we analyse the case in which an expansion of sector $G$ mere generates additional employment without creating any productive rural asset, in other words, the elasticity of the land efficiency function, i.e. $E_{h}=0$.

This policy of unproductive employment generation programme does not require capital, i.e. $\bar{a}_{K G}=0$. The level of employment in the non-traded sector, $G$ (located in region 1 ), is equal to $\bar{X}_{G}$. With the expansion of sector $G, \bar{X}_{G}$ rises and draws labour from sector 1 . This creates labour shortage in sector (region) $1 .{ }^{18}$ Consequently, the competitive wage, $W$ (in region 1), goes up, while the rental to arable land, $R$, falls. Labour shortage in sector 1 leads to the Rybczynski type effect (RTE), thereby leading to contraction of sector 1 and expansion of sector 2 both in terms of output and employment. ${ }^{19}$ Note that sector 1 is more labour intensive relative to the sector (region) 2 in the physical sense. Although the intersectoral wage differential has fallen, it cannot prevent the reverse migration of labour from sector 2 to sector 1 . Because of the contraction of both sectors at least, for the time being, all the reverse migrated workers do not find jobs in either of the two broad sectors of the economy. The net effect, therefore, will be a sharp increase in the urban unemployment level. The following proposition, therefore, readily follows.

Proposition 2 Additional employment generation in sector $G$ as a policy response to COVID-19 induced reverse migration, raises both competitive wage in sector 1 and unemployment level in sector 2 provided this policy do not create any productive rural infrastructure.

On the other hand, public spending is productive only if some amount of capital is utilized in the program located at region 1, i.e., $\bar{a}_{K G}>0$ and $E_{h}>0$. This leads to infrastructure development in region 1 which in turn leads to an increase in land productivity, $h$ thereby increasing the effective endowment of arable land $h()$.$N and expansion of sec-$ tor $G$ located in region 1. The expanding sector draws both labour and capital from the two traded sectors. Due to labour scarcity in sector (region) 1 , the competitive wage, $W$, in region 1, rises and sector 1 contracts. Besides, capital scarcity via $\boldsymbol{R T E}$ causes sector (region) 2 to contract both in terms of output, $X_{2}$ and employment, $L_{2}$ because it is the most capital-intensive sector (region). We, therefore, find that the expected urban (region 2) wage falls, while the competitive wage in sector (region) 1 has increased.

These have two implications on the level of urban unemployment. First, an increase in the agriculture sector wage rate, $W$, and contraction of sector 2 leads to a fall in the urban unemployment level. Second, the contraction of sector 1 owing to labour drain out by the public sector scheme (sector $G$ ) causes urban unemployment level to increase. We obtained

\footnotetext{
18 Note that both output and employment levels are equal in sector $G$. Both of them are equal to, $\bar{X}_{G}$. This is because the production technology is of the fixed-coefficient type and the labour-output ratio is equal to unity.

19 The term, ' $\boldsymbol{R} \boldsymbol{T E}$ ' has been explained in detail in footnotes 12, 13, 14 of Chaudhuri and Biswas (2016).
} 
that the net effect of urban unemployment level hinges on the relative factor abundance ratio between the urban region (region 2) and rural region (region 1) which also constitutes the necessary condition to determine the direction of variation. The unemployment level accentuates (plummet) if the urban sector is relatively more (less) labour abundant than the rural sector. ${ }^{20}$ This is implied by the following

$$
\left.\frac{\hat{L}_{U}}{\overline{\bar{X}}_{G}}\right|_{E_{h}>0}>(<) 0 \text { iff } \frac{\lambda_{L 2}+\lambda_{L U}}{\lambda_{K 2}}>(<) \frac{\lambda_{L 1}}{\lambda_{K 1}}
$$

The following proposition is now imminent.

Proposition 3: Employment generation programme with the creation of productive rural infrastructure in terms of higher land efficiency accentuates rural sector wage rate; however, the urban unemployment level accentuates (plummets) if the urban region is relatively more (less) labour abundant than the rural agriculture sector.

Let us now concentrate on policy effects on social welfare. Sector (region) 2 of this economy is distorted because of both labour market imperfection and the presence of unemployment. Additional job creation in region 1 without the creation of any rural infrastructure leads to an expansion of the distorted sector (region) and aggravates the unemployment problem. Consequently, national income, $Y$, unequivocally falls and social welfare measured using Sen (1974) index worsens under some sufficient condition. ${ }^{21}$ This can be explained as follows. The welfare measure is a positive function of mean income, $y$, and a negative function of the Gini inequality index, $g$. $g$ measures the inequality across each pair of groups in the population-weighted by their population share. An increase in the pool of unemployed labour earning zero wage rate widens the income disparity with respect to the other two groups employed in the rural region and the urban region. Thus, it accentuates the Gini index, $g$. The two forces of lowered $y$ and higher $g$ lower the welfare of the economy. Hence, the proposition readily follows.

Proposition 4: Rural employment generation programme without the creation of rural infrastructure lowers the welfare of the economy.

On the other hand, ours is a small open economy with multiple distortions. As per the standard trade theory, any policy change that is designed to correct a particular distortion might increase the degree of the other distortion. Hence, the net outcome on welfare could be ambiguous. ${ }^{22}$ In the present case, exactly this happens. Additional employment generation in region 1 with the creation of productive rural assets corrects distortion in sector (region) 2 although it creates a new distortion in the form of positive production externality in terms of improved land efficiency. No second instrument exists for taking care of this new distortion. Therefore, the welfare consequence is inconclusive. This is stated as follows.

\footnotetext{
${ }^{20}$ In India after the initial phase of lockdown which inflicted reversed migration caused a fall in level of urban unemployment rate from 24.95 per cent during April 2020 to November 2020. The effect of expansion of NREGP and post-unlock urban unemployment began to rise from the first week of December 2020 (CMIE, 2020).

21 See Appendix 6 for mathematical derivation of the effect on social welfare.

22 See Lipsey and Lancaster (1956), Bhagwati (1971) and Bhagwati and Srinivasan (1974) etc.
} 
Proposition 5: Employment generation programme with the creation of productive rural assets may not necessarily worsen welfare.

We use equation (A.21) to construct the following table (Table 2). Table 2 offers a set of reasonable numerical values corresponding to different parameters in the system for verifying the relationship between $\bar{X}_{G}$ and $L_{U}$ when $E_{h}>0$. Two different sets, viz. set 1 and set 2 , are considered to draw out the necessary condition of relative factor abundance between the urban region and the rural region. The numerical values in set 1 correspond to the situation when the urban sector is relatively more labour abundant and the numerical values in set 2 correspond to the situation when the rural agriculture sector is relatively more labour abundant. Within each set, three different sub-sets are considered by altering the numerical values of the parameters to show that our results are robust and hold under different consistent values of the parameters.

Figure 1 (red plots) corresponds to the numerical values in set 1 . The horizontal axis and the vertical axis measure the values of $E_{h}$ and $\hat{L}_{U} / \bar{X}_{G}$, respectively. The sub-sets simu1, simu2 and simu3 satisfy the condition $\lambda_{K 1}\left(\lambda_{L 2}+\lambda_{L U}\right)-\lambda_{L 1} \lambda_{K 2}>0$. simu 1 and simu2 satisfy the factor-intensity ranking assumption made in the model, while simu3 violates the factor-intensity ranking. Simu1, simu2 and simu3 are depicted by the solid red line, long-dashed red line and small-dashed red line, respectively. It is clear from Fig. 1 that all the three straight lines are in the first positive quadrant which implies that an expansion of $\bar{X}_{G}$ causes $L_{U}$ to increase for all positive range of values of $E_{h}$ which proves the counterproductive outcome. Simu3 violates factor-intensity ranking; however, it also lies in the first positive quadrant which proves $\lambda_{\underline{K} 1}\left(\lambda_{L 2}+\lambda_{L U}\right)-\lambda_{L 1} \lambda_{K 2}>0$ to be a sufficient condition for the counterproductive effect of $\bar{X}_{G}$ on $L_{U}$

On the other hand, Fig. 2 (blue plots) corresponds to the numerical values in set 2 . The condition of relative factor abundance between the urban and the rural region is reversed for the numerical values in the sub-sets in set 2 , i.e., $\lambda_{K 1}\left(\lambda_{L 2}+\lambda_{L U}\right)-\lambda_{L 1} \lambda_{K 2}<0$. It is evident from Fig. 2 that $\bar{X}_{G}$ has a favourable effect on $L_{U}$ since all the three curves lie in the fourth quadrant which implies that $\frac{\hat{L}_{U}}{\hat{\bar{X}}_{G}}<0 \forall E_{h}>0$. This proves that the relative factor abundance condition is also a necessary condition to determine the direction of variation.

\section{COVID-19 disaster, composite policy and concluding remarks}

A three-sector HT-type model has been developed for identifying factors that are responsible for the failure of the rural employment generation program, in the absence or presence of any natural disaster. A distinction has been made between two alternative modes of implementation of such a program. We have shown how any unplanned attempt to the creation of additional jobs (in region 1) not only accentuates unemployment but also worsens social welfare. On the contrary, if the creation of additional employment is accompanied by matching investment on infrastructure development in the rural sector, the policy unequivocally lowers unemployment. Besides, it does not necessarily lower welfare. Thus, we can infer that from the perspective of both unemployment and welfare, the implementation of the program via the second route seems appropriate. 
Table 2 Sensitivity of $\mathrm{L}_{\mathrm{U}}$ against $\bar{X}_{G}$ when $\mathrm{E}_{\mathrm{h}}>0$ for parametric changes

\begin{tabular}{lllllllllllll}
\hline & & $\lambda_{\mathrm{K} 1}$ & $\lambda_{\mathrm{K} 2}$ & $\lambda_{\mathrm{KG}}$ & $\lambda_{\mathrm{L} 1}$ & $\lambda_{\mathrm{L} 2}$ & $\lambda_{\mathrm{LG}}$ & $\mathrm{E}_{\mathrm{h}}($ range) & $\mathrm{S}_{\mathrm{NL}}^{1}$ & $\mathrm{~S}_{\mathrm{NL}}^{1}$ & $\theta_{\mathrm{N} 1}$ & $\theta_{\mathrm{L} 1}$ \\
\hline Set 1 (red plots) & simu1 & 0.078 & 0.068 & 0.853 & 0.04 & 0.03 & 0.03 & $0.1-1$ & 0.5 & 0.5 & 0.4 & 0.5 \\
& simu2 & 0.0398 & 0.026 & 0.934 & 0.04 & 0.04 & 0.03 & $0.1-1$ & 0.5 & 0.5 & 0.4 & 0.5 \\
& simu3 & 0.118 & 0.118 & 0.827 & 0.2 & 0.17 & 0.08 & $0.1-1$ & 0.5 & 0.5 & 0.4 & 0.5 \\
Set 2(blue plots) & simu4 & 0.228 & 0.331 & 0.441 & 0.43 & 0.22 & 0.28 & $0.1-1$ & 0.5 & 0.5 & 0.4 & 0.5 \\
& simu5 & 0.251 & 0.347 & 0.402 & 0.38 & 0.24 & 0.33 & $0.1-1$ & 0.5 & 0.5 & 0.4 & 0.5 \\
& simu6 & 0.21 & 0.358 & 0.432 & 0.45 & 0.19 & 0.29 & $0.1-1$ & 0.5 & 0.5 & 0.4 & 0.5 \\
\hline
\end{tabular}

Source: self-computation

The basic structure of this model might be useful in analysing the impact of the lockdown and Unlock 1 phase of the natural disaster, termed COVID-19, on the Indian labour market.

What policy the authority should now undertake at least for controlling further damage. First, there is an urgent need to strictly prohibiting return migration. Second, the hitherto adopted counterproductive policy of additional job creation has to be immediately replaced by direct cash transfer through net banking in favour of the people in distress. At this moment, it is to be understood that human lives are far more valuable vis-à-vis economic growth. The policy of direct financial assistance to the poor will automatically take care of demand deficiency. Consequently, the growth rate will automatically pick up soon after. Finally, the authority needs to undertake a dual policy comprising of taxing the superrich and redistribution of income in favour of the poor. It is to be seen whether the authority could be bold enough to resort to the composite policy that we have prescribed.

\section{Appendix 1: Some Useful Expressions}

Differentiating Eqs. (3 and 4), we, respectively, find that

$$
\begin{gathered}
\hat{r}=0 \\
\hat{P}_{G}=0
\end{gathered}
$$

Differentiating (5) and using (17), the following equation is obtained.

$$
\hat{r}^{*}=0
$$

Differentiating Eq. (2) and using (19), the following equation readily follows.

$$
\theta_{L 1} \hat{W}+\theta_{N 1} \hat{R}=0
$$

Differentiating Eqs. 6, 7 and 10, using (19) and after much mathematical simplification, the following expression follows.

$$
A_{2} \hat{W}+A_{3} \hat{R}=-\left[A_{4} \hat{\gamma}+A_{1} \hat{\bar{X}}_{G}\right]
$$

where 


$$
\begin{gathered}
A_{1}=\left[E_{h}\left\{\frac{\lambda_{L 1} \lambda_{K 2}-\left(\lambda_{L 2}+\lambda_{L U}\right) \lambda_{K 1}}{\lambda_{K 2}}\right\}-\left\{\frac{\left(\lambda_{L 2}+\lambda_{L U}\right) \lambda_{K G}-\lambda_{L G} \lambda_{K 2}}{\lambda_{K 2}}\right\}\right]<0 \\
A_{2}=\left[\left\{\frac{\left(\lambda_{L 2}+\lambda_{L U}\right) \lambda_{K 1}-\lambda_{L 1} \lambda_{K 2}}{\lambda_{K 2}}\right\} S_{N L}^{1}-\lambda_{L 1} S_{L N}^{1}-\left(\lambda_{L 2}+\lambda_{L U}\right)\right] \\
A_{3}=\left[\left\{\frac{\lambda_{L 1} \lambda_{K 2}-\left(\lambda_{L 2}+\lambda_{L U}\right) \lambda_{K 1}}{\lambda_{K 2}}\right\} S_{N L}^{1}+\lambda_{L 1} S_{L N}^{1}\right] ; \text { and, } \\
A_{4}=\left[\lambda_{L U}+\lambda_{L 2}\right]>0
\end{gathered}
$$

Arranging expressions (20) and (21) in a matrix notation, we get

$$
\left[\begin{array}{ll}
\theta_{L 1} & \theta_{N 1} \\
A_{2} & A_{3}
\end{array}\right]\left[\begin{array}{l}
\hat{W} \\
\hat{R}
\end{array}\right]=\left[\begin{array}{l}
0 \\
-\left(A_{4} \hat{\gamma}+A_{1} \hat{\bar{X}}_{G}\right)
\end{array}\right]
$$

\section{Appendix 2: Policy effects on factor prices}

Solving (24), we obtain the following expressions.

$$
\begin{aligned}
& \hat{W}=\left(\frac{\theta_{N 1}}{\Delta}\right)\left[A_{4} \hat{\gamma}+A_{1} \hat{\bar{X}}_{G}\right] \\
& \hat{R}=-\left(\frac{\theta_{L 1}}{\Delta}\right)\left[A_{4} \hat{\gamma}+A_{1} \hat{\bar{X}}_{G}\right]
\end{aligned}
$$

where

$$
\Delta=\left[\theta_{L 1} A_{3}-\theta_{N 1} A_{2}\right]
$$

From expressions (25 and 26) and using (27), the effects of policy changes on the factor prices are obtained as follows.

$$
\begin{aligned}
\left(\frac{\hat{W}}{\hat{\gamma}}\right) & =\left(\frac{\theta_{N 1} A_{4}}{\Delta}\right) \\
\left(\frac{\hat{W}}{\hat{\bar{X}}_{G}}\right) & =\left(\frac{\theta_{N 1} A_{1}}{\Delta}\right) \\
\left(\frac{\hat{R}}{\hat{\gamma}}\right) & =-\left(\frac{\theta_{L 1} A_{4}}{\Delta}\right)
\end{aligned}
$$




$$
\left(\frac{\hat{R}}{\hat{\bar{X}}_{G}}\right)=-\left(\frac{\theta_{L 1} A_{1}}{\Delta}\right)
$$

\section{Appendix 3: Policy outcomes on output composition}

Differentiating Eqs. (6, 7 and 10), using (19, 22, 23) and (25-27) and after much manipulation, the following results can be derived.

$$
\begin{gathered}
\left(\frac{\hat{X}_{1}}{\hat{\gamma}}\right)=-\left[\frac{\left(\theta_{L 1}+\theta_{N 1}\right) A_{4} S_{N L}^{1}}{\Delta}\right] \\
\left(\frac{\hat{X}_{1}}{\hat{\bar{X}}_{G}}\right)=E_{h}-\left[\frac{A_{1}\left(\theta_{N 1}+\theta_{L 1}\right) S_{N L}^{1}}{\Delta}\right] \\
\left(\frac{\hat{X}_{2}}{\hat{\gamma}}\right)=\left(\frac{\lambda_{K 1}}{\lambda_{K 2}}\right)\left[\frac{A_{4}\left(\theta_{L 1}+\theta_{N 1}\right) S_{N L}^{1}}{\Delta}\right] \\
\left(\frac{\hat{X}_{2}}{\hat{\bar{X}}_{G}}\right)=-\frac{\left(\lambda_{K G}+\lambda_{K 1} E_{h}\right)}{\lambda_{K 2}}+\frac{\lambda_{K 1} S_{N L}^{1} A_{1}\left(\theta_{N 1}+\theta_{L 1}\right)}{\lambda_{K 2} \Delta}
\end{gathered}
$$

\section{Appendix 4: Consequences on unemployment}

Total differentiating Eq. (11) yields the following.

$$
\hat{L}_{U}=\frac{\lambda_{L 2}}{\lambda_{L U}}\left[\hat{X}_{2}\left(\frac{\gamma W^{*}}{W}-1\right)+\left(\frac{\gamma W *}{W}\right) \hat{\gamma}-\left(\frac{\gamma W^{*}}{W}\right) \hat{W}\right]
$$

after much simplification, the following two results are obtained:

$$
\begin{gathered}
\left(\frac{\hat{L}_{U}}{\hat{\gamma}}\right)=\frac{\lambda_{L U}+\lambda_{L 2}}{\lambda_{L U}}+\frac{A_{4} S_{N L}^{1} \lambda_{K 1}\left(\theta_{N 1}+\theta_{L 1}\right)}{\lambda_{K 2} \Delta}-\frac{A_{4} \theta_{N 1}}{\Delta}\left(\frac{\lambda_{L U}+\lambda_{L 2}}{\lambda_{L U}}\right) \\
\left(\frac{\hat{L}_{U}}{\hat{\bar{X}}_{G}}\right)=\frac{\lambda_{K 1} S_{N L}^{1} A_{1}\left(\theta_{N 1}+\theta_{L 1}\right)}{\lambda_{K 2} \Delta}-\frac{A_{1} \theta_{N 1}\left(\lambda_{L U}+\lambda_{L 2}\right)}{\Delta}-\frac{\lambda_{K G}+\lambda_{K 1} E_{h}}{\lambda_{K 2}}
\end{gathered}
$$




\section{Appendix 5: Consequences on national income}

Differentiating (12), we get

$$
d Y=P_{1} d X_{1}+P_{2} d X_{2}
$$

Differentiating the production functions, we can write the following.

$$
d Y=P_{1}\left(F_{L}^{1} d L_{1}+F_{N}^{1} d N_{1}\right)+r * d K_{1}+P_{2}\left(F_{L}^{2} d L_{2}+F_{K}^{2} d K_{2}\right)
$$

Now differentiating the factor endowment equations and noting that factors of production are paid according to their value of marginal products, from (40), we obtain the following.

$$
d Y=\left[W d L_{1}+R d N_{1}+r^{*} d K_{1}+W^{*} d L_{2}+r d K_{2}\right]
$$

Simplifying and considering the envelope property of the HT structure, we obtain

$$
d Y=\left[W d \bar{L}+R d \bar{N}+\left(r^{*}-r\right) d K_{1}\right]
$$

or, $d Y=\left[\left(r^{*}-r\right) a_{K 1} d X_{1}\right](40)$.

[Note that $a_{K 1}$ is technologically given and that the endowments of the three factors of production are exogenously fixed. In other words, we have $d N=d \bar{L}=d \bar{K}=0$ ].

Using (32)-(35), from (36) the following results are obtained:

$$
\begin{gathered}
\left(\frac{d Y}{d \gamma}\right)=\left[\frac{\left(r^{*}-r\right) a_{K 1} X_{1}\left(\theta_{L 1}+\theta_{N 1}\right) A_{4} S_{N L}^{1}}{\gamma \Delta}\right] \\
\left(\frac{d Y}{d \bar{X}_{G}}\right)=\frac{\left(r^{*}-r\right) a_{K 1} X_{1}}{\bar{X}_{G}}\left[E_{h}-\frac{S_{N L}^{1} A_{1}\left(\theta_{N 1}+\theta_{L 1}\right)}{\Delta}\right]
\end{gathered}
$$

\section{Appendix 6: Derivation of the expression for welfare and policy consequences}

Substituting Eq. (1, 2, 3, 4, 5, 6, 7, 8) in Eq. (12) and assuming $\bar{L}=1$, we get

$$
y=W\left(L_{1}+\bar{X}_{G}\right)+W^{*} L_{2}+\left(r^{*}-r\right) K_{1}+r \bar{K}+R h\left(\bar{a}_{K G} \bar{X}_{G}\right) \bar{N}-\left(W+r \bar{a}_{K G}\right) \bar{X}_{G}
$$

Using envelope property of the Harris-Todaro migration equilibrium (45) boils down to

$$
y=W+\left(r^{*}-r\right) K_{1}+r \bar{K}+R h\left(\bar{a}_{K G} \bar{X}_{G}\right) \bar{N}-\left(W+r \bar{a}_{K G}\right) \bar{X}_{G}
$$

Using the frequency distribution table (Table 1) and equation, (46) we get

$$
y g=L_{1} \bar{X}_{G}(\bar{W}-W)+L_{1} L_{2}\left(W^{*}-W\right)+L_{1} L_{U} W+L_{2} \bar{X}_{G}\left(W^{*}-W\right)+\bar{X}_{G} L_{U} \bar{W}+L_{2} L_{U} W^{*}
$$

Taking total derivative of Eq. (13)

$$
d S=d y-d(y g)
$$


Total derivative of equation (47) yields

$$
d(y g)=\hat{\bar{X}}_{G} A_{10}+\hat{\gamma} A_{11}
$$

where

$$
\begin{gathered}
A_{5}=\left(W^{*}-W\right)\left(\lambda_{L 1}+\lambda_{L G}\right) \lambda_{L 2}+W^{*} \lambda_{L 2} \lambda_{L U}>0 \\
A_{6}=\left(W^{*}-W\right) \lambda_{L 1} \lambda_{L 2}+(\bar{W}-W) \lambda_{L G} \lambda_{L 1}-W \lambda_{L 1} \lambda_{L G} \\
A_{7}=\lambda_{L 1} \lambda_{L G}(\bar{W}-W)>0 \\
A_{8}=\lambda_{L U}\left[W^{*} \lambda_{L 2}+W\left(\lambda_{L 1}+\lambda_{L G}\right)\right]>0 \\
A_{9}=\lambda_{L 1}\left[W^{*} \lambda_{L 2}+\lambda_{L U}-\lambda_{L 2}-\lambda_{L G}+\bar{W} \lambda_{L 1}\right] \\
\left.+\frac{S_{N L}^{1} A_{1}}{\Delta}\right)\left(\theta_{L 1}+\theta_{N 1}\right)\left[\frac{A_{5} \lambda_{K 1}}{\lambda_{K 2}}-A_{6}+\frac{A_{7} \lambda_{K 1}}{\lambda_{K 2}}-A_{8}\right] \\
+E_{h}\left[A_{6}-\frac{A_{5} \lambda_{K 1}}{\lambda_{K 2}}-\frac{A_{7} \lambda_{K 1}}{\lambda_{K 2}}\right]-\frac{A_{5} \lambda_{K G}}{\lambda_{K 2}}-I\left[\frac{A_{1} \theta_{N 1}\left(\lambda_{L U}+\lambda_{L 2}\right)}{\Delta}+\frac{\lambda_{K G}}{\lambda_{K 2}}\right] \\
A_{11}=\frac{A_{4} S_{N L}^{1}\left(\theta_{N 1}+\theta_{L 1}\right)}{\Delta}\left[A_{5}\left(\frac{\lambda_{K 1}}{\lambda_{K 2}}+1\right)+A_{6} \frac{\lambda_{K 1}}{\lambda_{K 2}}-A_{7}\right]+A_{8}\left(\frac{\lambda_{L U}+\lambda_{L 2}}{\lambda_{L U}}\right)\left(1-\frac{A_{4} \theta_{N 1}}{\Delta}\right)
\end{gathered}
$$

Substituting (48, 43 and 44 in (48), we get

$$
\begin{gathered}
\left(\frac{d S}{d \bar{X}_{G}}\right)=\left(\frac{1}{\bar{X}_{G}}\right)\left[\left(r^{*}-r\right) a_{K 1} X_{1}\left(E_{h}-\frac{\left(\theta_{N 1}+\theta_{L 1}\right) S_{N L}^{1} A_{1}}{\Delta}\right)-A_{10}\right] \\
\left(\frac{d S}{d \gamma}\right)=\left(\frac{1}{\gamma}\right)\left[\frac{A_{4} S_{N L}^{1}\left(\theta_{N 1}+\theta_{L 1}\right)}{\Delta}-A_{11}\right]
\end{gathered}
$$




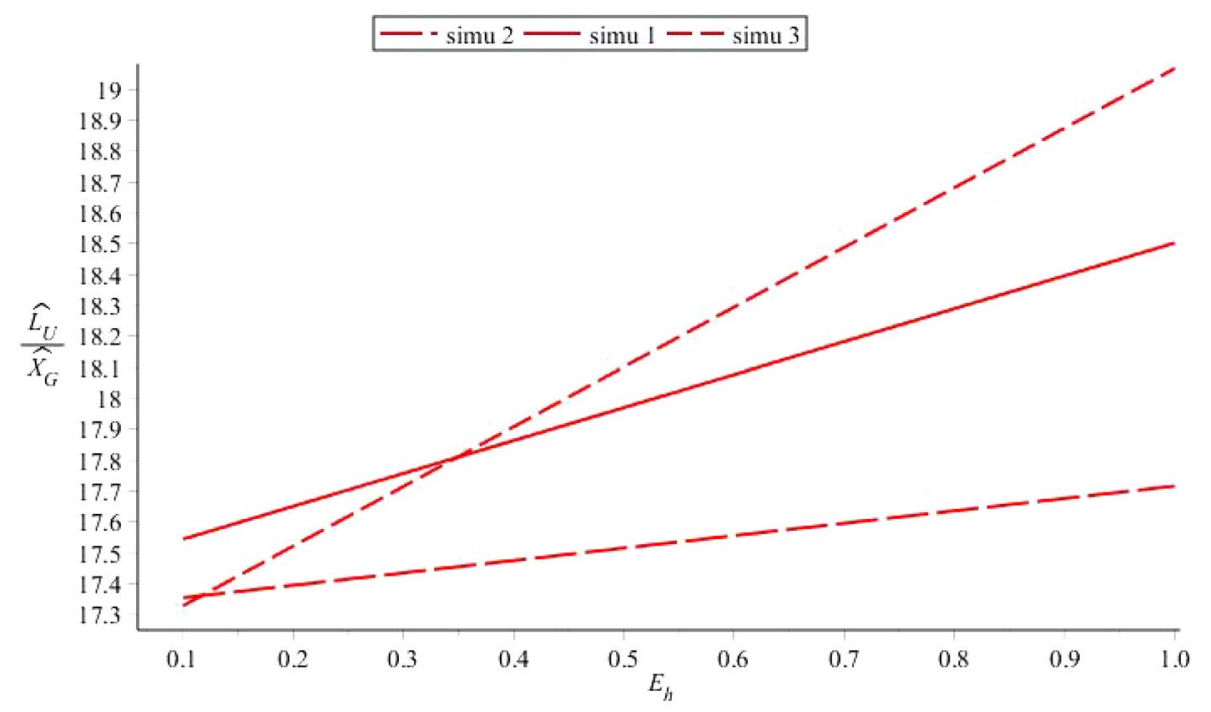

Fig. 1 Effect of public sector employment generation programme on urban unemployment in the presence of land efficiency for different parametric values of $\lambda_{\mathrm{ji}}$ corresponding to set 1

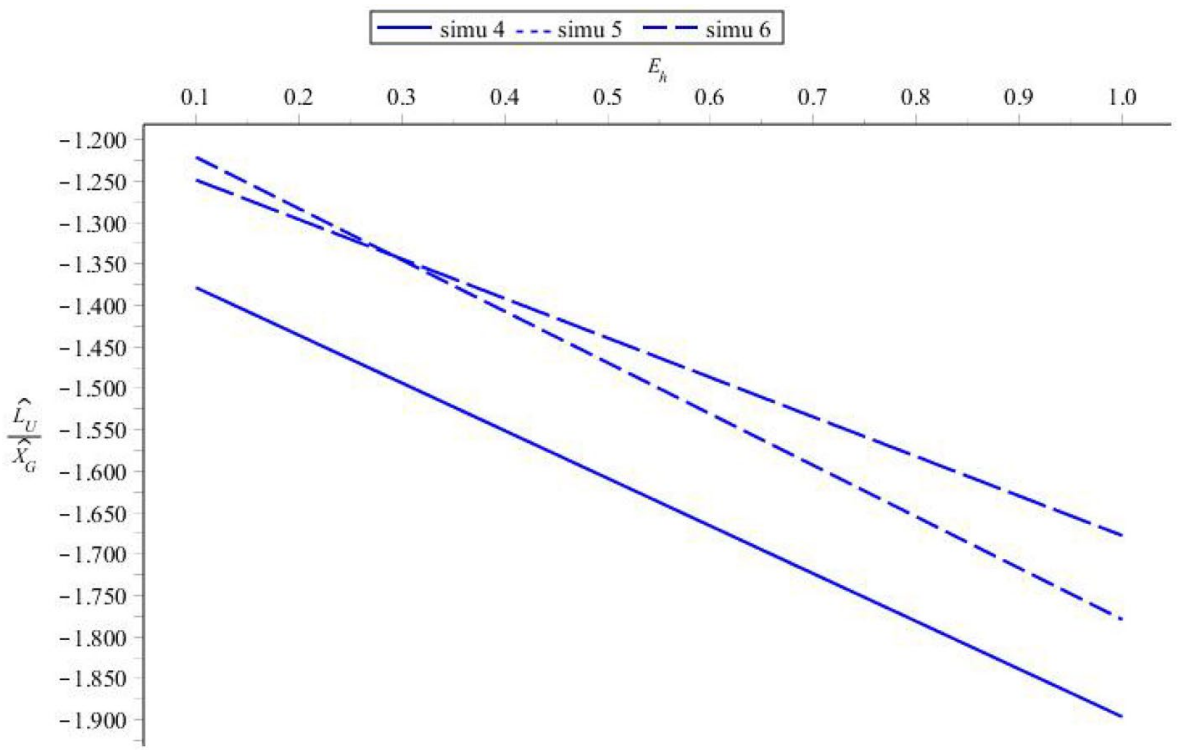

Fig. 2 Effect of public sector employment generation programme on urban unemployment in the presence of land efficiency for different parametric values of $\lambda_{\mathrm{ji}}$ corresponding to set 2 
Acknowledgements The authors are indebted to the two anonymous reviewers of this journal whose comments helped improve and clarify this paper. The authors are also grateful to Prof. Ranjanendra Narayan Nag for his constructive comments and useful suggestions on the earlier draft of the paper. (Late) Prof. Sarbajit Chaudhuri formulated the key ideas and structure of the theoretical model in this paper. Unfortunately, he passed away in April, 2021. The other two authors (S. Mahata and S. Chaudhuri) are indebted to Prof. Sarbajit Chaudhuri for his substantial contribution to the paper beside acting as an academic supervisor to the other two authors. The authors remember him with great fondness and love. However, the usual disclaimer applies.

Funding None.

Data availability Numerical data set had been provided within the main text in the manuscript.

\section{Declarations}

Conflicts of interests The authors declare that they have no conflict of interests.

\section{References}

Ambasta P, Shankar P, Shah M (2008) Two years of NREGA: The road ahead. Econ Pol Wkly 43(8):41-50

Basu A (2013) Impact of rural employment guarantee schemes on seasonal labor markets: optimum compensation and workers' welfare. J Econ Inequal 11:1-34

Basu A, Chau N, Kanbur R (2009) A theory of employment guarantees: contestability, credibility and distributional concerns. J Public Econ 93:482-497

Beladi H, Naqvi N (1988) Urban unemployment and non-immiserizing growth. J Dev Econ 28(3):365-376

Berg E, Bhattacharyya S, Durgaram R, Ramachandra M (2012) "Can rural public works affect agricultural wages? Evidence from India". CSAE Working Paper.

Bhagwati J, Srinivasan T (1974) On reanalyzing the Harris-Todaro model: policy rankings in the case of sector-specific sticky wages. American Economic Review 64:502-508

Bhagwati J (1971) "The generalized theory of distortions and welfare". In: JN Bhagwati, RW Jones, R Mundell, J Vanek (eds), Trade, Balance of Payments and Growth; Papers in International Economics in Honor of Charles P. Kindleberger. Amsterdam, North-Holland.

Bhattacharjee G (2017) MGNREGA as distribution of dole. Econ Pol Wkly 52(25 \& 26):29-33

Chakravarty SR, Dutta B (1990) Migration and welfare. Eur J Polit Econ 6:119-138

Chaudhuri S (2003) How and how far to liberalize a developing economy with informal sector and factor market distortions. J Int Trade Econ Dev 12(4):403-428

Chaudhuri S (2011) Economic recession, skilled unemployment and welfare. Econ Model 28(3):1435-1440

Chaudhuri S (2017) How could the credibility of the Harris-Todaro model be improved. Rev Urban Regional Develop Stud 29(3):196-216

Chaudhuri S, Biswas A (2016) Endogenous labour market imperfection, foreign direct investment and external terms-of-trade shocks in a developing economy. Econ Model 59(3):416-424

Chaudhuri S, Dwibedi J (2017) Subsidizing healthcare in the presence of market distortions. Econ Model 64:539-552

Chaudhuri S, Gupta M (2014) International factor mobility, informal interest rate and capital market imperfection: a general equilibrium analysis. Econ Model 37:184-192

CMIE (2020). "Unemployment rate in India: Statistical Profiles". Center for Monitoring Indian Economy, Retrieved from https://unemploymentinindia.cmie.com/ .

Dasgupta D, Rajeev M (2020) Paradox of supply-constrained Keynesian equilibrium: the COVID-19 case. Econo Polit Week 55(22):22-27

Datar C (2007) Failure of national rural employment guarantee scheme in Maharashtra. Econ Pol Wkly 42(34):3454-3457

ETNOWNEWS. (2020, August 09). Retrieved from https://www.timesnownews.com/business-economy/economy/ article/how-the-covid-19-outbreak-has-affected-the-joblessness-rate-in-india-explained-in-4-charts/634284

Gupta M (1988) Migration, welfare, inequality and shadow wage. Oxf Econ Pap 40:477-486. https://doi. org/10.1093/oxfordjournals.oep.a041866

Gupta M (1993) Rural-urban migration, informal sector and development policies: a theoretical analysis. J Dev Econ 41:137-151 
Gupta M (1994) Foreign capital, income inequality and welfare in a Harris-Todaro model. J Dev Econ 45(2):407-414

Harris J, Todaro M (1970) Migration, unemployment and development: a two-sector analysis. Am Econ Rev 60(1):126-142

Imbert C, Papp J (2015) Labor market effects of social programs: evidence from India's employment guarantee. Am Econ J Appl Econ 7(2):233-263

Lipsey R, Lancaster K (1956) The general theory of second best. Rev Econ Stud 24(1):11-32

Mahata, S. , Khan, R.K., Nag, R.N. (2020) Economic recession informal sector and skilled-unskilled wage disparity in a developing economy: A trade-theoretical analysis. Foreign Trade Review 55(2):168-188. https://doi.org/10.1177/0015732519894132

Marjit, S., \& Acharyya, R. (2003). "Diverse trade pattern, complementarity and fragmentation". In International trade, wage inequality and the developing economy. Heidelberg: Physica.

Ministry of Rural Development, Government of India (2012), MGNREGA Sameeksha: An anthropology of research studies on the Mahatma Gandhi National Rural Employment Guarantee Act, 2005, 2006-12, (ed) Mihir Shah, Neelakshi Mann and Varad Pande, Orient Black Swan, New Delhi. https://nrega.nic. in/Circular_Archive/archive/MGNREGA_SAMEEKSHA.pdf

Mukhopadhyay A, Himanshu, Sharan MR (2015) NREGS in Rajasthan: rationed funds and their allocation across villages. Econ Polit Wkly 50(6):52-60

Nagaraj N, Bantilan C, Pandey L, Roy N (2016) Impact of MGNREGA on rural agricultural wages, farm productivity and net returns: an economic analysis across SAT villages. Ind J Agri Econ 71(2):176-190

Pankaj A (2017) Shift in MGNREGS from UPA to NDA. Econ Pol Wkly 52(34):59-68

Ravallion M (1990) Market response to anti-hunger policies Effect on wages, prices and employment. In: Dreze J, Sen A (eds) The political economy of hunger. Oxford University Press Inc, New York

Sen A (1974) Informal bases of alternative welfare approaches: aggregation and income distribution. J Public Econ 4:387-403

The Economic Times. (2020, July 22). Retrieved from https:/economictimes.indiatimes.com/news/econo my/indicators/pandemic-to-bite-deeply-gdp-to-shrink-by-6-per-cent-in-fy21-report/articleshow/77106 074.cms

The World Bank (2020). "The global economic outlook during the COVID-19 pandemic: A changed world". Retrieved from worldbank.org: https:/www.worldbank.org/en/news/feature/2020/06/08/theglobal-economic-outlook-during-the-covid-19-pandemic-a-changed-world

Zimmermann, L. (2012, September). "Labor market impacts of a large-scale public works program: Evidence from Indian employment guarantee scheme". IZA Institute of Labor Economics, IZA DP No. 6858. Retrieved from https://www.iza.org/: http://ftp.iza.org/dp6858.pdf

Publisher's Note Springer Nature remains neutral with regard to jurisdictional claims in published maps and institutional affiliations. 